\title{
Estudos sobre fungos micorrízicos
}

\author{
$\overline{\text { Vênia C. de Souza }{ }^{1} \text {, Ricardo A. da Silva² }{ }^{2} \text { Gleibson D. Cardoso }{ }^{3} \text { \& Artur F. Barreto }}{ }^{4}$
}

\section{RESUMO}

Este artigo faz uma abordagem sobre as interações micorrízicas, caracteriza os tipos de fungos micorrízicos, identifica os pontos importantes na utilização prática desses fungos e apresenta informações atualizadas sobre o assunto. As técnicas da ciência moderna formaram as bases da micorrizalogia, que se espalhou pelo mundo e representa, hoje importante ramo interdisciplinar das Ciências Biológicas, com grandes possibilidades para a exploração comercial, com o objetivo de aumentar a produção de madeira, fibras e alimentos e reduzir os custos e o impacto dos sistemas modernos de produção sobre o meio ambiente. O Brasil, em função de suas condições edafo-climáticas, aptidões agrossilvopastoril e a escassez de recursos financeiros, apresenta enorme potencial para utilização de micorrizas, uma vez que o uso de micorrizas promove ganhos de produção e, conseqüentemente, retorno financeiro.

Palavras-chave: associação, microorganismos, colonização, simbiose

\section{Studies on mycorrhizal fungi}

\begin{abstract}
This article elaborates the mycorrhizal interactions, characterizes the types of mycorrhizal fungi and identifies the important points in the practical use of these fungi and shows information brought up to date on the subject. The techniques of modern Science formed the bases of the mycorrhizalogy that spread in world and today represents an important branch of Biological Sciences, with great possibilities for the commercial scanning, aiming to magnify the wood production, vegetable fibers and foods and to reduce the costs and the impact of modern systems of production on environment. The Brazil, due to its edafoclimatic conditions, agricultural, forestal and pastoral aptitudes and the scarcity of financial resources presents enormous potential for use of mycorrhiza, since it promotes production and consequently financial rollback.
\end{abstract}

Key words: association, microorganism, colonization, symbiosis

${ }^{1}$ Bióloga, DCBS/UFPB, CEP 58.220-000, Bananeiras, PB. Fone: (83) 3367-1200. E-mail: venia@areianet.com.br

${ }^{2}$ Ciência do Solo. Escola Agrícola de Jundiaí, UFRN, Macaíba, CEP: 59280-000, RN, Fone: (84) 271-1113. E-mail: ralencarsilva@yahoo.com.br

3 Doutorando em Agronomia. Jaboticabal, SP, CEP 14884-900. Fone: (016) 3209-2704. E-mail: gleibson75@hotmail.com

${ }^{4}$ Engenheiro Agrônomo. Rua Izaura Dantas Pinheiro, S/N. Jardim Adalgiza II, Cajazeiras, PB, CEP 58.900-000. Fone: (83) 3531-3315. E-mail: arturfrancbarr@bol.com.br 


\section{INTRODUÇÃO}

Com a expansão demográfica dos últimos anos, a necessidade do uso de recursos do planeta está sendo maximizada representando, atualmente, grande desafio para a ciência. O solo é um desses recursos e, juntamente com seus organismos, contribui de modo decisivo para a manutenção da vida e para o equilíbrio da biosfera. Seu estudo tem sido intensificado nas últimas décadas, sobretudo nos aspectos relacionados aos seus organismos dentre os quais se destacam os simbiontes, tais como as micorrizas e as bactérias fixadoras de nitrogênio, por exercerem significativo papel para a funcionalidade e manutenção dos ecossistemas naturais manejados e principalmente degradados. Pesquisas envolvendo esses organismos têm, como objetivo prático, aumentar a produção, reduzir o uso de fertilizantes químicos e contribuir para alcançar um padrão de agricultura mais sustentável e menos dependente de insumos (Siqueira \& Moreira, 1996).

A associação entre raízes e determinados fungos do solo, denominada micorriza, ocorre na maioria das espécies vegetais superiores. O termo micorriza foi, de início, proposto pelo botânico alemão Albert Bernard Frank, em 1885, originado do grego, em que "mico" significa fungo e "riza" raízes. Esta associação já era conhecida há pelo menos 50 anos antes de Frank, mas considerada de natureza parasítica. Para Frank, as micorrizas representavam um fenômeno de ocorrência generalizada, resultante da união orgânica entre as raízes e o micélio de fungos a um órgão morfologicamente independente, com dependência fisiológica íntima e recíproca, seguida pelo crescimento de ambas as partes e com funções fisiológicas muito estreitas, sendo consideradas o mais inesperado e surpreendente fenômeno da natureza.

Ele ainda especulou sobre o possível envolvimento da associação na nutrição e crescimento das plantas, consideração esta refutada por outros estudiosos da época, que a consideravam estritamente parasítica. O pesquisador, porém, demonstrou, em 1894, de maneira convincente, que a colonização das raízes das árvores pelos fungos resultava em micélio abundante na rizosfera, o que ajudava a absorver nutrientes do solo e do húmus, e que o fungo era incapaz de atacar, injuriar ou causar qualquer disfunção nas raízes, caracterizando a natureza mutualista da associação (Siqueira \& Franco, 1988).

Esses estudos foram confirmados pelas técnicas da ciência moderna e se constituiu nas bases da micorrizalogia, que se espalhou pelo mundo inteiro e representa, hoje, um importante ramo interdisciplinar das Ciências Biológicas, com enormes possibilidades para a exploração comercial, visando aumentar a produção de madeira, fibras e alimentos e, ainda, reduzir os custos financeiros e o impacto dos sistemas modernos de produção sobre o meio ambiente.

Certos fungos desempenham papel crucial na nutrição mineral de plantas vasculares. Caso as plântulas de muitas árvores que crescem em solução esterilizada, contendo nutrientes, sejam transplantadas em solo proveniente de mata, crescerão pobremente e poderão, eventualmente, morrer por má nutrição; no entanto, se uma pequena quantidade $(0,1 \%$ do volume) do solo de floresta contendo os fungos apropria- dos for adicionada ao redor das raízes das mudas, estas crescerão normalmente (Raven et al., 1996).

A restauração do crescimento normal é causada pelo estabelecimento de micorrizas, que são associações íntimas, mutuamente benéficas e simbióticas, entre fungos e raízes. As micorrizas ocorrem na maioria dos grupos de plantas vasculares; apenas poucas famílias de plantas fanerogâmicas não apresentam micorrizas; estas incluem a família da mostarda (Brassicaceae) e a dos juncos (Cyperaceae). As raízes densas e muito finas de Proteaceae parecem desempenhar papel relevante, semelhante às micorrizas de outras plantas.

Muitas plantas parecem crescer normalmente quando são supridas com elementos essenciais, em especial fósforo, mesmo se as micorrizas estiverem ausentes; no entanto, se os elementos essenciais estiverem presentes em quantidades limitadas, plantas que não têm micorrizas crescem pobremente ou não crescem. A habilidade das micorrizas de absorver e transportar fósforo do solo foi demonstrada em experimentos em que se utilizou o ${ }^{32} \mathrm{p}$ radiativo. O incremento na absorção de zinco, manganês e cobre, três outros nutrientes essenciais, foi igualmente demonstrado (Raven et al., 1996)

Desde que a rede de hifas das micorrizas se estenda vários centímetros para além da zona colonizada pelas raízes, as plantas se tornam aptas a obter nutrientes a partir de volume de solo muito maior do que seria possível sem as micorrizas. O fungo se beneficia da associação, obtendo carboidratos da planta hospedeira (Raven et al., 1996).

O objetivo deste estudo foi apresentar uma abordagem sobre os fungos micorrízicos, os quais capacitam as plantas para melhor sobrevivência e crescimento contribuindo, desta forma, para o sucesso das populações vegetais.

\section{CLASSIFICAÇÃO DAS MICORRIZAS}

Há 2 grupos principais de micorrizas: Endomicorrizas e ectomicorrizas.

As endomicorrizas são as mais comuns, ocorrendo em cerca de $80 \%$ das plantas vasculares. O fungo componente é um zigomiceto; com menos de 200 espécies envolvidas em tais associações; amplamente distribuídas por todo o mundo; assim, as relações endomicorrízicas não são altamente específicas. A hifa do fungo penetra nas células corticais da raiz da planta, onde são formadas pequenas estruturas densamente ramificadas, com aspecto de minúscula árvore (arbúsculos ou dilatações denominadas vesículas). As endomicorrizas são freqüentemente chamadas fungos micorrízicos arbusculares. A maioria ou quase todas as trocas entre fungos e plantas ocorre nos arbúsculos. A hifa se estende para o solo por vários centímetros, aumentando significativamente a quantidade absorvida de fosfato e outros nutrientes essenciais (Raven et al., 1996).

As ectomicorrizas são características de certos grupos de árvores e arbustos encontrados principalmente em regiões temperadas. Este grupo inclui a família das faias e carvalhos (Fagaceae); a família dos salgueiros, álamos e choupos (Salicaceae) e a família dos pinheiros (Pinaceae) além de certos grupos de árvores tropicais que formam densos 
Tabela 1. Características diferenciais dos principais tipos de micorrizas

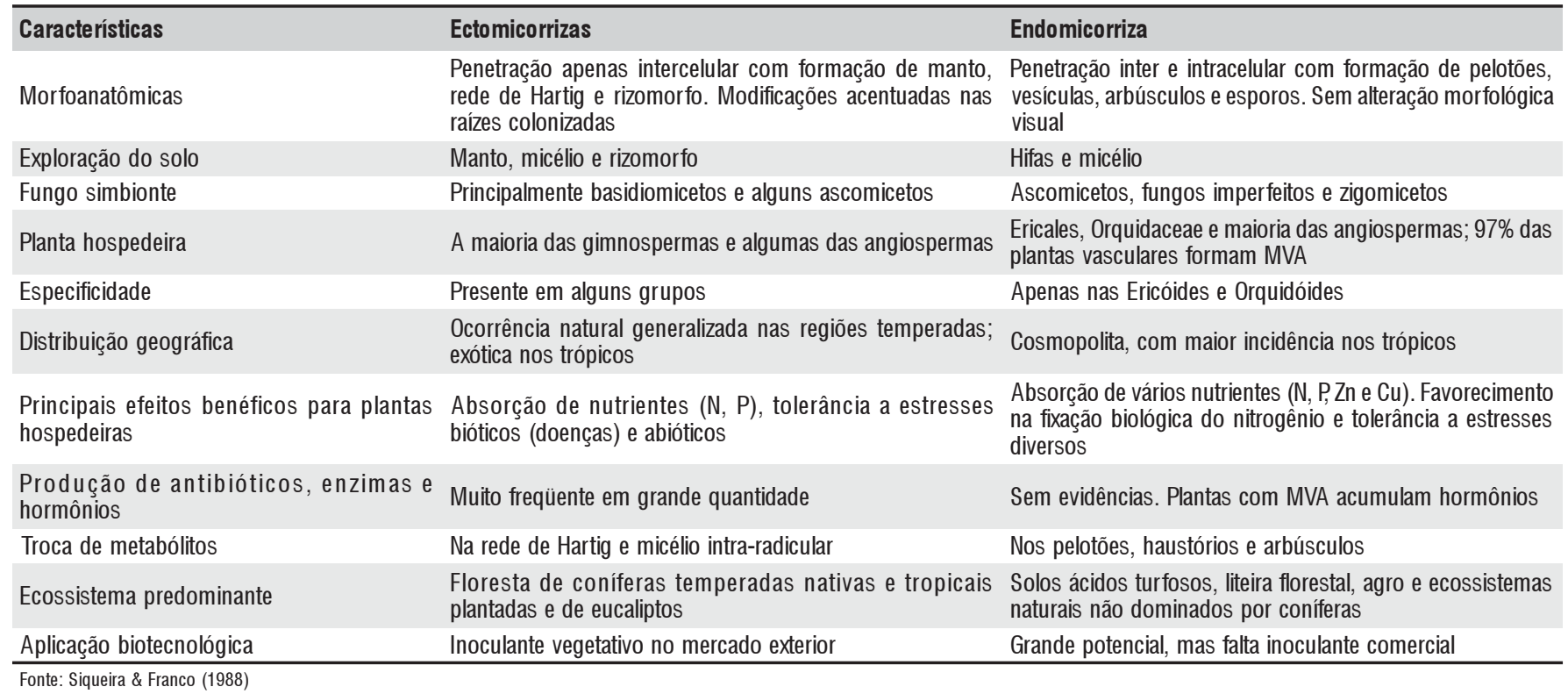

agregados puros. Essas árvores que crescem em diferentes partes do mundo, freqüentemente são ectomicorrízicas. A associação micorrízica aparentemente torna as árvores mais resistentes às rigorosas condições de frio e de seca que ocorrem nas zonas limites de crescimento das árvores.

O fungo envolve mas não penetra nas células vivas das raízes. As hifas crescem entre as células do córtex da raiz, formando uma estrutura característica, a rede de Hartig, a qual, eventualmente, circunda muitas das células corticais. A presença da rede de Hartig parece prolongar a vida, tanto das células como da raiz, esta funciona como interface entre o fungo e a planta. Em adição a esta estrutura, as raízes são circundadas por um manto de hifas a partir do qual cordões miceliais se estendem para o solo vizinho.

Nas raízes com ectomicorrizas, os pêlos estão geralmente ausentes, sendo suas funções aparentemente desempenhadas pelas hifas. As ectomicorrizas são, em sua maioria, formadas por basidiomicetos, incluindo muitos gêneros de cogumelos, mas algumas envolvem associações com ascomicetos, inclusive trufas.

Pelo menos 5.000 espécies de fungos estão envolvidas nas associações ectomicorrízicas, geralmente com alto grau de especificidade (Raven et al., 1996). Outro aspecto a considerar é que muitos fungos ectomicorrízicos são, comprovadamente, fonte de alimento para animais em florestas temperadas e tropicais (Taylor, 1991), participando de maneira decisiva na manutenção da estabilidade de comunidades florestais (Hawksworth, 1991).

As características diferencias entre os tipos de micorrizas são apresentadas na Tabela 1.

\section{BIOLOGIA DAS MICORRIZAS}

Evidências de que os vegetais ancestrais já tinham micorrizas, indicam que plantas e fungos micorrízicos passaram por um processo de co-evolução, o que explica a ocorrência generalizada, as diferenciações em tipos e a distribuição geográfica dessas associações. Do ponto de vista ecológico e sob considerações práticas, as ectomicorrizas e endomicorrizas são as mais importantes (Siqueira \& Franco, 1988).

Nas ectomicorrizas, o estabelecimento da simbiose ectomicorrízica se inicia pela ativação dos propágulos do fungo que, no caso de esporos, germinam e formam um tufo de hifas na rizosfera, colonizando a superfície das raízes e, finalmente, penetrando-a através das junções celulares na Zona de Infecção Micorrízica (ZIM), que se localiza logo atrás da zona meristemática apical da raiz. Após a penetração, as hifas colonizam o córtex intercelularmente, por meio da digestão enzimática da lamela média com ocupação de todo o espaço intercelular, dando origem à rede de Hartig, que é intra-radicular, ao manto e ao rizomorfo, que são extra-radiculares. Todos esses tecidos resultam de diferenciações morfológicas no micélio do fungo.

A penetração e interação fungo-planta promovem modificações acentuadas no hábito de crescimento e morfologia dos segmentos de raízes colonizadas, o que permite a detecção visual das ectomicorrizas. O processo de micorrização é dinâmico e segue o crescimento e desenvolvimento das raízes; ao mesmo tempo em que os segmentos micorrizados mais velhos entram em senescência, os novos se tornam colonizados, em função do potencial de inóculo na rizosfera, da fisiologia da planta e das condições ambientais.

Uma vez estabelecida a colonização primária, ela tende a se perpetuar, pelo acompanhamento do crescimento apical da raiz, da colonização secundária, resultante do micélio extra-radicular e da elevação do potencial de inóculo na rizosfera (Siqueira \& Franco, 1988).

Nas endomicorrizas não se verificam modificações anatômicas resultantes da invasão das raízes pelo fungo; portanto, não são reconhecidas a olho nu, o que difere das ectomicorrizas, porém as raízes de algumas plantas, como 
cebola e milho e representantes da família Liliaceae, tornam-se amareladas quando micorrizadas.

Observações microscópicas mostram que os fungos penetram nas células corticais das raízes sem causar danos, o que os diferencia dos fungos patogênicos, fato também verificado nos outros tipos de micorrizas com penetração intracelular.

A formação da associação se inicia a partir da interface formada entre os propágulos do fungo no solo, que podem ser esporos, células auxiliares e hifas que crescem de raízes colonizadas (infecção secundária). Dos propágulos, formam-se as hifas infectivas que, estimuladas pelos componentes bióticos dos exudatos e pelas condições fisico-químicas da rizosfera, crescem abundantemente, aumentando as chances de contacto entre a raiz e o fungo. Essas hifas, ao encontrarem as raízes, aderem à sua superfície (epiderme ou pêlos radiculares) e formam um apressório, através do qual penetram as células da epiderme na zona de diferenciação e alongamento, formando a "unidade de infecção". A partir deste ponto, as hifas se espalham pelo córtex intercelularmente, através da lamela média tornando-se, posteriormente, intracelulares, quando formam as hifas enoveladas nas camadas mais externas do córtex, diferenciando-se em arbúsculos nas camadas mais internas e, finalmente, em vesículas e esporos.

A velocidade de espalhamento, diferenciação intra e extra radicular e esporulação, é relativamente rápida e depende do genoma da planta hospedeira e da espécie de fungo envolvida, além das condições do meio ambiente, sobretudo do solo.

Além das estruturas intra-radiculares, externamente é formada uma rede de hifas ou micélio, células auxiliares e esporos. O micélio é dimórfico, em geral não septado, de coloração amarelada e com diâmetro variando de 2 a $27 \mu \mathrm{m}$. Ele se ramifica no solo, permanecendo contínuo à fase intra-radicular, localizado no córtex. O desenvolvimento e o espalhamento deste micélio na rizosfera são determinados pelo fungo, condições ambientais e idade da planta ou da simbiose, sendo de grande importância para o funcionamento da associação, além de representar uma extensão do órgão de absorção das plantas com vantagens geométricas e espaciais em relação às raízes absorventes. A quantidade de micélio extra-radicular pode atingir até $1,5 \mathrm{~m} \mathrm{~cm}^{-1}$ de hifa de raiz colonizada, ou $55 \mathrm{~m} \mathrm{~g}^{-1}$ de solo rizosférico (Siqueira \& Franco, 1988).

\section{SUCESSÃO DE FUNGOS ECTOMICORRÍZICOS EM FLORESTAS E PLANTAÇÕES}

Além da especificidade fungo - hospedeiro, as ectomicorrizas apresentam fenômenos de sucessão dos fungos em função da idade das plantas. As primeiras observações sobre este aspecto se devem a pesquisadores da "Edinburg University," Escócia (Mason et al., 1982; Last et al., 1984). A partir dos resultados dessas observações, os fungos ectomicorrízicos são separados em 2 grupos: nos de estádio inicial e nos de estádio tardio. Danielson (1984) acrescentou um terceiro grupo: o dos fungos multiestádios, representado pelos fungos presentes durante todo o ciclo de vida das plantas.
Estudos mostraram que os fungos de estádio tardio são incapazes de colonizar raízes de plântulas em solo não estéril (Deacon et al., 1983), a menos que elas estejam situadas próximas a árvores adultas já colonizadas por esses fungos (Fleming, 1983), porém a colonização pode ocorrer em condições de síntese micorrízica in vitro ou de solo estéril (Fleming, 1985). Nas duas últimas situações, os fungos de estádio tardio desaparecem do sistema radicular, quando as plântulas são transferidas para o campo (Last et al., 1984).

Entre as várias hipóteses para explicar a sucessão, as mais discutidas relacionam este fenômeno ao atendimento das exigências nutritivas do fungo pela planta hospedeira (Gibson \& Deacon, 1990). Supõe-se, neste caso, que fungos de estádios tardios apresentam maior demanda de açúcares que aqueles de estádio inicial, o que dificultaria sua associação a plantas jovens, em condições naturais e em ausência de árvores adultas. Os fungos de estádio inicial, além de sua reduzida demanda por carboidratos do hospedeiro, utilizariam os outros nutrientes, preferencialmente na forma mineral, que é mais abundante nos solos de povoamento jovem. Os fungos de estádio tardio, por sua vez, teriam maior demanda por carboidratos e preferência por nutrientes orgânicos, forma mais abundante nos solos de povoamento adulto. Como última diferença, as interações com a microbiota do solo passariam de interações competitivas a interações sinérgicas, respectivamente, nos fungos de estádio inicial e tardio.

No Brasil, Giachini \& Oliveira (1996) observaram casos de sucessão em plantações de Pinus spp. Nesse estudo, realizado em plantações de diferentes idades, as frutificações de certos fungos, como Amanita spp., Lactarius spp. e Suillus spp. foram observadas predominantemente nos plantios de idade avançada. Por outro lado, encontraram-se frutificações de Rhizopogon spp. com exclusividade nas plantações jovens. Outros fungos, como Laccaria spp. e a maioria das espécies de Scleroderma, parecem constituir o grupo multiestádios, tendo sido observado em plantações de todas as idades.

\section{APLICAÇÃO DOS FUNGOS ECTOMICORRÍZICOS}

O caráter mutualístico da associação ectomicorrízica resulta em vários benefícios para os organismos envolvidos. A dinâmica da simbiose reflete-se no favorecimento da absorção, translocação e utilização de nutrientes e água, podendo haver modificações na taxa de crescimento das raízes, assim como efeitos indiretos sobre o solo e a microbiota associada (Garbaye \& Dupponois, 1992). Os benefícios podem proporcionar melhoria do crescimento das plantas, além de lhes favorecer o estabelecimento em locais normalmente impróprios ao seu crescimento (Delwaulle et al., 1987).

O interesse por essas associações se intensificou nas últimas décadas, como conseqüência da crise de energia e de suas implicações na produção de fertilizantes e da preocupação crescente da sociedade com o impacto do uso indiscriminado de produtos químicos no meio ambiente; também contribuiu, para tal, a descoberta de que o sucesso na introdução de certas plantas, como é o caso de espécies exóticas, ou na 
recuperação de solos degradados, dependia da introdução de fungos micorrízicos compatíveis com elas.

A exploração das simbioses micorrízicas surgiu, assim, como alternativa de menor impacto ambiental ao uso de produtos químicos para auxiliar o estabelecimento e o crescimento das plantas (Oliveira \& Giachini, 1999).

\section{CONTROLE DOS FUNGOS ECTOMICORRÍZICOS}

As ectomicorrizas predominam em seis famílias, nas quais se encontram as espécies mais utilizadas em silvicultura no mundo. Em geral, o povoamento dessas plantas ocupa solos de baixa fertilidade, justificando a busca de técnicas para melhorar a sobrevivência, a tolerância ao estresse e, por conseguinte, a produtividade das plantações; assim, é necessário o conhecimento prévio das espécies e tipos micorrízicos existentes, da seleção de fungos eficazes na promoção do crescimento e sobrevivência das plantas sob diferentes condições de ambiente (solo, clima, etc.), tal como da capacidade de monitoramento dos fungos introduzidos nos sistemas radiculares.

A predominância dos efeitos positivos e sua ordem de magnitude confirmam o enorme potencial do controle da micorrização para o sistema de produção de mudas no setor florestal. Dentre os fungos empregados no controle de micorrização na maioria dos países, destaca-se o Pisolithus spp (Aggangan et al., 1996). O sucesso de Pisolithus tinctorius na promoção do crescimento de coníferas nos Estados Unidos (Marx et al., 1992) levou outros países ao uso indiscriminado dessa espécie ou de espécies afins, para inoculação de outras essências florestais, como Eucalyptus spp. Em muitas ocasiões, a escolha de Pisolithus spp para inoculação tem sido feita sem nenhum estudo comparativo em relação a outras espécies ectomicorrízicas, chegando-se a usar, isolados americanos de $P$. tinctorius para inoculação de plantas decíduas em países tropicais. À medida em que o conhecimento aumenta em termo da diversidade dos fungos ectomicorrízicos, em diferentes ecossistemas e regiões do planeta, não se entende o investimento de grande parte da pesquisa e experimentação em uma única espécie ou gênero de fungo. São requeridos, portanto, estudos comparativos sobre a infectividade e a eficiência de isolados de Pisolithus spp. e de outros fungos ectomicorrízicos em plantações brasileiras, em relação aos diferentes hospedeiros e às diferentes condições edafo-climáticas, antes de se decidir pela escolha de tais fungos para inoculação (Oliveira \& Giachini, 1999).

Vieira \& Peres (1990), ao estudarem o teor adequado de fósforo extraível em um solo de cerrado, visando à seleção de fungos e o efeito de $P$. tinctorius e de seis fungos ectomicorrízicos isolados de plantios de Pinus spp. no crescimento de mudas de Pinus caribaea var. hondurensis, demonstraram que para a seleção de fungos ectomicorrízicos eficientes, deve-se utilizar um nível de fósforo baixo, ou seja, em torno de 2,72 ppm de fósforo extraível.

Os autores concluíram que o nível de fósforo no substrato não afetou a formação de micorrizas pelo fungo Pisolithus tinctorius 299 nas mudas de P. caribaea var. honduren- sis; o efeito da simbiose no hospedeiro, embora se manifestasse em todos os níveis de $\mathrm{P}$, diminuiu de intensidade com o aumento do nível de P no substrato e os fungos ectomicorrízicos isolados na região do Cerrado são de baixa eficiência simbiótica em relação ao Pisolithus tinctorius.

\section{INOCULANTES ECTOMICORRÍZICOS}

Vários tipos de inoculantes ectomicorrízicos são produzidos e testados nas últimas décadas, dentre os quais se destacam os inoculantes "naturais", representados pelo uso do solo de plantações (Mikola, 1973) e de esporos fúngicos (Marx \& Cordell, 1990) e os inoculantes micelianos ou vegetativos (Marx, 1980).

Esses inoculantes apresentam uma série de desvantagens, destacando-se a eficiência desconhecida dos fungos introduzidos e o risco de contaminação com patógenos. Quanto aos esporos, só podem ser obtidos de fungos que esporulam em abundância e, como acontece com o inoculante solo, não permitem assegurar a eficiência dos fungos empregados; entretanto, tais inoculantes têm dado importante contribuição à silvicultura, em alguns países.

Tendo em vista as desvantagens dos inoculantes naturais, desenvolveram-se pesquisas na tentativa de se ampliar inoculantes alternativos. No estádio atual, os inoculantes micelianos, em que o micélio fúngico produzido em cultura axênica, aplicado ao substrato de plantio pode ser adotado para produção de inoculante de qualquer fungo que possa ser isolado e cultivado em meio artificial e, ainda, permite testar previamente a infectividade e eficiência dos fungos em relação à planta de interesse, antes de sua introdução nos sistemas de produção de mudas (Marx, 1980).

A produção de inoculantes micelianos de fungos ectomicorrízicos, é feita, em geral, em uma mistura turfa-vermiculita embebida de uma solução nutritiva em frascos de vidro, ou em sacos plásticos, munidos de um dispositivo especial de aeração do meio (Marx et al., 1992).

A vermiculita é um material de baixo custo e de fácil utilização, mas seu pH neutro é muito elevado para o crescimento de fungos ectomicorrízicos, o que pode ser compensado pela adição de turfa. Este método é pouco viável quando se trata da produção de grande quantidade de inoculante, normalmente necessária para inocular o enorme volume de mudas produzidas pelas empresas florestais (Smith \& Read, 1997).

Uma técnica mais sofisticada consiste no cultivo desses fungos em fermentadores em meio líquido, com posterior inclusão do micélio num gel, geralmente alginato de cálcio, e se baseia no processo clássico de imobilização de células microbianas (Maupérin et al., 1987). Estudos em viveiros demonstraram que este inoculante encapsulado é mais eficiente que o sólido (turfa-vermiculita), provavelmente pela maior proteção do micélio no interior do gel contra fatores bióticos e abióticos, além de apresentar maior facilidade de armazenamento, transporte e maior longevidade do fungo permitindo, desta forma, reduzir a quantidade a ser empregada para inoculação das plantas (Kuek et al., 1992). Este 
procedimento é promissor, mas sua utilização contínua é restrita, devido as dificuldades na multiplicação dos fungos ectomicorrízicos por processos de fermentação líquida.

A França iniciou, recentemente, a produção de inoculante ectomicorrízico em larga escala, por este método, em que o fungo é cultivado em meio líquido em biorreator e, em seguida, fragmentado e encapsulado em alginato de cálcio. Apenas 100 mg de micélio são suficientes para inocular $1 \mathrm{~m}^{2}$ de viveiro (Oliveira \& Giachini, 1999).

\section{INOCULANTES DE FUNGOS MICORRÍZICOS ARBUSCULARES}

Os fungos micorrízicos arbusculares (FMA), considerados de ocorrência generalizada nos solos e na maioria das plantas vasculares, beneficiam o crescimento das plantas por absorver nutrientes do solo, aumentando a resistência das mesmas, nos períodos de seca, e das mudas, na ocasião do transplante (Jeffries, 1987 apud Aquino \& Cassiolato, 2002). Resultados obtidos por Silva et al. (2004) demonstararam que Gigaspora albida promoveu respostas significativas no crescimento de mudas de maracujazeiro-doce (Passiflora alata Curtis).

As recomendações de manejo da micorriza arbuscular dizem respeito aos fungos micorrízicos arbusculares existentes no solo e visam ao aumento de sua população. A aplicação desses fungos em grandes áreas deve ser através da inoculação, que ainda é restringida pela baixa disponibilidade de inoculantes comerciais. A principal dificuldade para a produção de inoculante comercial com qualidade deve-se ao fato de os FMAs serem biotróficos obrigatórios, isto, é, só completam o seu ciclo de vida associados a um hospedeiro vegetal vivo. Eles não podem ser multiplicados em um meio de cultura definido, à semelhança da obtenção de inoculantes de rizóbios fixadores de nitrogênio atmosférico. Como não existe tecnologia adequada para produção de inoculantes de FMAs, não há grande interesse comercial pela sua produção e distribuição, limitando o seu uso na agricultura (Saggin Júnior \& Lovato, 1999). Ainda de acordo com os autores, técnicas alternativas para a multiplicação dos FMAs têm sido desenvolvidas e até patenteadas, utilizando-se plantas hospedeiras ou cultura de raízes. As principais (In vitro, em hidropônica e em substrato) visam obter um inoculante mais puro, livre de solo ou, pelo menos, mais leve que os produzidos cultivando a planta hospedeira diretamente no solo.

A prática de inoculação é mais recomendada na produção de mudas em viveiro, onde ela é necessária porque para a produção de mudas, utiliza-se, com freqüência, subsolo ou solo esterilizado para eliminar os patógenos, que, paralelamente, também são eliminados os fungos micorrízicos arbusculares nativos. Outros substratos utilizados em viveiro, como a vermiculita e materiais orgânicos, são igualmente desprovidos desse fungo. Quanto ao crescimento das mudas, a maioria das espécies arbustivas e arbóreas tropicais, frutíferas com micorriza desenvolvem-se mais rapidamante, ficando menos tempo no viveiro e podendo ser disponibilizadas mais cedo para o produtor. Além disso, elas são mais tolerantes ao estresse do transplante apresentando maior sobrevivência no campo. Finalmente, essa prática permite, também, reduzir a quantidade e aumentar a eficiência de uso dos corretivos e fertilizantes adicionados nos substratos. Um grande número dessas espécies arbóreas se beneficiam da inoculação. Entre elas pode-se citar: café, manga, acerola, abacate, mamão, maracujá, pequi, baru, jacarandá-da-bahia, sucupira, eucalipto, palmeiras como: buriti, guariroba, e forrageiras como: leucena, além das espécies arbóreas destinadas à recuperação das matas de galeria e de áreas degradadas (Miranda, 2005).

\section{CONCLUSÕES}

1. São necessárias pesquisas na área de aplicação biotecnológica dos inoculantes ectomicorrízicos em larga escala, no setor de reflorestamento, sobretudo no Brasil, e seleção de espécies de MVA com elevada efetividade e ou eficiência simbiótica e competitividade, além de, tecnologias economicamente viáveis para produção, armazenamento e aplicação do inoculante.

2. O Brasil apresenta enorme potencial para utilização de micorrizas, se consideradas as condições edafo-climáticas, as aptidões agro-silvo-pastoril e a escassez de recursos financeiros, tornando-se esta tecnologia viável.

3. O uso de micorrizas promove ganho de produção e, conseqüentemente, retorno financeiro. A utilização das micorrizas será intensificada quando a tecnologia se tornar conhecida e a oferta ou o custo dos fertilizantes se tornar limitante.

\section{LITERATURA CITADA}

Aggangan, N. S.; Dell, B.; Malajczuk, N.; De la Cruz, R. Soil fumigation and phosphorus supply affect the formation of Pisolithus-Eucalyptus urophylla ectomycorrhizas in two acid Philippine soils. Plant Soil, Dordrecht, p.259-266, 1996.

Aquino, S. S.; Cassiolato, A. M. R.Contribuição de fungos micorrízicos arbusculares autóctones no crescimento de Guazuma ulmifolia em solo de cerrado degradado. Pesquisa Agropecuária Brasileira. Brasília, v.37, n.12, p.1819-1823, 2002.

Danielson, R. M. Ectomycorrhizal associations in jack pine stands in north-eastern Alberta. Canadian Journal of Botany, Ottawa, v.62, n.5, p.932-939, 1984.

Deacon, J. W.; Donaldson, S. J.; Last, F. T. Sequences and interactions of mycorrhizal fungi in birch. Plant and Soil, Dordrecht, v.71, p.257-262, 1983.

Delwaulle, J. C.; Diangana, D.; Garbaye, J. Augmentation de la production du pin des caraibes dans la region côtiere du Congo par l'introduction du champignon Pisolithus tinctorius. Revue Forestieres Française, Paris, v.5, p.409-417, 1987.

Fleming, L. V. Sucession of mycorrhizal fungi on birch: Infection of seedlings planted around mature trees. Plant and Soil, Dordrecht, v.71, p.263-267, 1983.

Fleming, L. V. Experimental study of sequences ectomycorrhizal fungi on birch (Betula sp) seedling root systems. Soil Biological Biochemical, Oxford, v.17, n.5, p.591-600, 1985.

R. Bras. Eng. Agríc. Ambiental, v.10, n.3, p.612-618, 2006. 
Garbaye, J.; Duponnois, R. Specificity and function of mycorrhization helper bacteria (MHB) associated with the Pseudotsuga menziesii- Laccaria laccata symbiosis. Symbiosis, Rehovot, v.14, p.335-344, 1992.

Giachini, A. J.; Oliveira, V. L. Ectomycorrhizal fungi in Eucalyptus and Pinus Plantations in Santa Catarina (Southern Brazil) In: International Conference on Mycorrhizas 1, Berkeley. Abstract... University of California,1996. p.52

Gibson, F.; Deacon, J. W. Establishment of ectomycorrhizas in aseptic culture: Effects of glucose, nitrogen and phosphorus in relation to sucessions. Mycological Research, Cambridge, v.94, p.166-172, 1990.

Hawksworth, D. L. The fungal dimension of biodiversity: Magnitude, significance, and conservation. Mycological Research, Cambridge, v.95, p.641-655, 1991.

Kuek, C.; Tommerup, I.; Malajczuk, N. Hydrogel bead inocula for the production of ectomycorrhizal eucalypts for plantations. Mycological Research, Cambridge, v.96, p.273-277, 1992.

Last, F. T.; Mason, P.A.; Ingleby, K.; Fleming, L. V. Sucession of fruitbodies of sheating mycorrhizal fungi associated with $\mathrm{Be}$ tula pendula. Forest Ecology Management, Amsterdam, v.9, n.1, p.229-234, 1984.

Marx, D. H. Ectomycorrhizal fungus inoculations: a tool for improving forestation practices In: Mikola, P. (ed). Tropical Mycorrhiza Research. Oxford: Clarendon Press, 1980, p.13-71.

Marx, D. H.; Cordell, C. E. Development of Pisolithus tinctorius ectomycorrhizae on loblolly pine seedlings from spores sprayed at different times and rates. Madison: USDA, Forest Service, 1990, 7p. Research note, SE-356

Marx, D. H.; Maul, S. B.; Cordell, C. E. Aplication of specific ectomycorrhizal fungi world forestry. In: Leatham, G. F. (ed). Frontiers in Industrial Mycology. New York: Chapman \& Hall, 1992, p.78-98.

Mason, P. A.; Last, F. T.; Pelham, J.; Ingleby, K. Ecology of some fungi associated with na ageing stand of birches (Betula pendula and B. pubescens). Forest Ecology Management, Amsterdam, v.4, n.1, p.19-39, 1982.

Maupérin, C.; Mortier, F.; Garbaye, J.; Le Tacon, F.; Carr, G. Viability of an ectomycorrhizal inoculum produced in a liquid medium and entrapped in a calcium alginate gel. Canadian Journal of Botany, Ottawa, v.65, n.11, p.2326-2329, 1987.
Mikola, P. Application of micorrhizal symbiosis in forestry practices. In: Marks, G. C.; Kozlowski, T. T. (eds.). Ectomycorrhizae, their ecology and physiology. New York: Academic Press, 1973. p.383-411.

Miranda, J. C. C. Importância da micorriza para a reprodução agrícola, frutífera e florestal. Ciência e Pesquisa-Artigos Técnicos. http://www.aviculturabrasil.com.br/Cietec/artigosTexto.asp. 30 Agost. 2005.

Oliveira, V.L.; Giachini, A.J. Ecologia e aplicação de ectomicorrizas. In: Siqueira, J.O. (Coord.). Inter-relação fertilidade: biologia do solo e nutrição de plantas. Viçosa: SBCS, Lavras: UFLA/DCS, 1999, p.775-796.

Raven, P. H.; Evert, R. F.; Eichhorn, S. E. Biologia vegetal. 5.ed. Rio de Janeiro: Guanabara Koogan S.A., 1996. 728p.

Saggin-Júnior, O. J.; Lovato, P. E. Aplicação de micorrizas arbusculares na produção de mudas e plantas micropropagadas. In: Siqueira, J. O. (Org.). Inter-relação fertilidade, biologia do solo e nutrição de plantas. Viçosa: SBCS, Lavras: UFLA/DCS, 1999. 818p.

Silva, M. A.; Cavalcante, U. M. T.; Silva, F. S. B.; Soares, S. A. G.; Maia, L. C. Crescimento de mudas de maracujazeiro-doce (Passiflora alata Curtis) associadas a fungos micorrízicos arbusculares (Glomeromycota). Acta Botânica Brasílica. São Paulo, v.18, n.4, p.981-985, 2004.

Siqueira, J. O.; Franco, A. A. Biotecnologia do solo: fundamentos e perspectivas. Brasília: MEC/ABEAS/ESAL/FAEPE, 1988, 236p

Siqueira, J. O.; Moreira, F. M. S. Microbiologia do solo e sustentabilidade agrícola: enfoque em fertilidade do solo e nutrição vegetal. In: Reunião Brasileira em Fertilidade do Solo e Nutrição de Plantas, 22, 1996, Manaus. Resumos... Manaus: SBCS,1996, p.1-42.

Smith, S. E.; Read, D. J. Micorrhizal symbiosis. 2.ed. London: Academic Press, 1997. 605p.

Taylor, R. J. Plants, fungi and bettongs: a fire dependent co-evolutionary relationship. Australian Journal Ecology, Oxon, v.16, n.3, p.409-411, 1991.

Vieira, R. F.; Peres, J. R. R. Fungos ectomicorrízicos para $\mathrm{Pi}$ nus spp. cultivados em solos sob vegetação de cerrado. Revista Brasileira de Ciência do Solo, Campinas, v.14, n.1, p.33-39, 1990. 